\title{
Chat Educacional: Que Espaço é Esse?
}

\author{
Alexandra Fogli Serpa GERALDINI ${ }^{1}$ \\ Faculdade de Comunicação e Filosofia da PUC-SP
}

Resumo: Este artigo objetiva contribuir para o desenvolvimento de uma metodologia de análise de bate-papos (ou chats) educacionais. Para tanto, a configuração do espaço interacional é descrita a partir da identificação do conteúdo temático e de seu desenvolvimento. São igualmente observados os fluxos interacionais e os papéis desempenhados pelos participantes. Os resultados revelam a possibilidade e a necessidade de partir de conhecimento acumulado na área e de dados provenientes do próprio meio digital para a elaboração de uma proposta mais adequada ao meio. Algumas sugestões são feitas no que diz respeito à constituição da interação digital síncrona.

Palavras-chave: metodologia de análise, chat educacional, conteúdo temático, fluxo interacional, sistemas de turnos

Abstract: The aim of this paper is to contribute to the development of an analysis methodology for (educational) chats. In order to do so, the constitution of this interactional tool is described, from the thematic content identification and its development. Interactional flow and participants' roles are also considered. The results reveal the possibility and the need to begin with previous knowledge in the area and also from data originated in the digital context in order to provide a proposal adequate to the context. Suggestions related to the constitution of the synchronous digital interaction are presented.

Key words: analysis methodology, educational chat, thematic content, interactional flow, turn taking system

Resumen: Este artículo tiene como objetivo contribuir al desarrollo de una metodología de análisis de chats educacionales. Para ello, se

\footnotetext{
${ }^{1}$ Departamento de Francês da Faculdade de Comunicação e Filosofia da PUC/ SP.
} 
describe la configuración del espacio de interacción, a partir de la identificación del contenido temático y de su desarrollo. Se observan también los flujos interactivos y los papeles desempeñados por los participantes. Los resultados revelan la posibilidad y la necesidad de partir del conocimiento acumulado en el área y de datos que provengan del propio medio digital para la elaboración de una propuesta más adecuada al medio. Asimismo, se hacen algunas sugerencias en cuanto a la constitución de la interacción digital síncrona.

Palabras-clave: metodología de análisis, chat educacional, contenido temático, flujo interactivo, sistemas de turnos

\section{Introdução}

A sociedade contemporânea tem sido o palco de processos de mudança nas áreas econômica, social, cultural, política, religiosa, institucional e mesmo filosófica. Nesse contexto dinâmico, observa-se um avanço espantoso das Novas Tecnologias da Informação e Comunicação (NTIC) ${ }^{2}$ que, além de inaugurar novas formas de comunicação e veiculação de informação, influenciam as formas de organizar e produzir conhecimentos.

Nesse quadro de mudanças caracterizado por uma cultura cada vez mais mediatizada e mundializada, o papel da educação, bem como suas finalidades maiores, encontra-se em transformação, uma vez que, das gerações que se encontram, hoje, na escola, espera-se um novo tipo de atuação profissional e exercício da cidadania. Para tanto, aponta-se, entre outros, a necessidade de formação contínua dos profissionais (D’AMBRÓSIO, 1999; KENSKI, 2001; MORAES, 2002).

Nesse sentido, entendemos que a discussão já existente a respeito da organização e resultados do sistema educacional no Brasil (CELANI, 1984; FREIRE, 1999; BRASIL, 1998; D'AMBRÓSIO, 1999) e em escala mundial (GÓMEZ, 1992; DELORS, 1998; SCHÖN, 1997) é apenas reforçada pela introdução das Tecnologias da Informação e Comunicação (TIC) na escola.

\footnotetext{
${ }^{2}$ Referimo-nos especialmente à tecnologia eletrônica, com destaque para a informática, o computador e a internet.
} 
No Brasil, a partir do início da década de 80 , atividades de pesquisa e discussões em pequena escala a respeito do uso do computador no processo pedagógico marcam o desenvolvimento da Política de Informática Educativa (PIE) (CARNEIRO, 2002). Essas atividades foram ampliadas pelo surgimento de projetos de pesquisa desenvolvidos em algumas universidades, ${ }^{3}$ com apoio do Governo.

A partir da década de 90, em orientações presentes nos PCNs, ${ }^{4}$ o governo brasileiro vem incentivando o uso das novas tecnologias nas escolas, bem como a necessidade do desenvolvimento de pesquisas que possibilitem seu uso crítico por parte de alunos e professores.

A Educação a Distância adquire, nesse panorama, importância significativa não apenas como uma forma de superar problemas pontuais, mas como uma alternativa para atender demandas de públicos específicos e, conforme aponta Belloni (1999, p. 5), assume

funções de crescente importância especialmente no ensino póssecundário, ou seja, na educação da população adulta, incluindo o ensino superior regular e toda a grande e variada demanda de formação contínua gerada pela obsolescência acelerada da tecnologia e do conhecimento.

Em linhas gerais, especialistas da área expõem que os potenciais oferecidos pelo novo contexto, como a flexibilidade de horários e a possibilidade de atender a um público infinitamente maior, são algumas das vantagens apresentadas, as quais contribuiriam para gerar uma maior democratização do ensino. Porém, a contrapartida é a presença de limitações como, por exemplo, a imprescindibilidade de disciplina e autonomia, por parte dos alunos, e a falta de preparo dos professores para atuar em cursos desse tipo.

O contexto digital de ensino caracteriza-se por alguns elementos marcantes: 1) grande fluxo e disponibilidade de acesso à informação; 2) rápido e simples armazenamento de dados; 3) liberdade

\footnotetext{
${ }^{3}$ Neste período, UNICAMP, UFPE, UFRGS, UFMG e UFRJ desenvolveram pesquisas que focalizavam principalmente o uso do programa Logo.

${ }^{4}$ Parâmetros Curriculares Nacionais.
} 
em relação aos horários de acesso e realização de atividades; e 4) favorecimento de um intercâmbio comunicativo intenso entre os membros da comunidade virtual.

Em função dessas características, diversos aspectos da Educação a Distância e do uso da telemática na educação têm sido focalizados por pesquisadores de forma geral, como a questão da avaliação dos cursos online (FREIRE et al., 2004), do processo de design (WADT, 2002), das potencialidades oferecidas pelo meio para o processo educacional (MARTINS FONTES, 2002), do uso das ferramentas interacionais - e-mail, fórum e chat - (BUZATO, 2001; SABBAG, 2002; PITOMBEIRA, 2003; FERREIRA; COLLINS, 2004; COLLINS et al., 2003), do percurso digital realizado pelos alunos (CARELLI, 2003) do papel do professor (FREIRE; RAMOS, 2001; GERALDINI, 2003).

Embora a Comunicação Mediada por Computador (CMC) não seja exatamente nova, seu uso era limitado antes do advento da rede. ${ }^{5}$ Contudo, a facilidade de acesso vem gerando aumento significativo na oferta de ferramentas e esse fato tem contribuído para estimular o uso do meio, inclusive em ambientes educacionais.

Uma decorrência direta dessa situação é o interesse crescente, por parte de pesquisadores e educadores em geral, a respeito do novo ambiente educacional e de seus elementos constitutivos. Todavia, defendemos, juntamente com Marcuschi (2002) e Lupiccini (2002), a necessidade de desenvolvimento de estudos etnográficos, que enfoquem a comunicação no meio virtual. Os autores destacam, igualmente, a necessidade de pensar nas conseqüências da tecnologia em uma perspectiva menos tecnicista e mais sócio-histórica.

\footnotetext{
${ }^{5}$ Estamos usando esse termo como sinônimo de internet, em seu sentido amplo, conforme definido no Dicionário Aurélio - Século XXI, versão eletrônica: "Qualquer conjunto de redes de computadores ligadas entre si por roteadores e gateways, como, p. ex., aquela de âmbito mundial, descentralizada e de acesso público, cujos principais serviços oferecidos são o correio eletrônico (q. v.), o chat (q. v.) e a Web (q. v.), e que é constituída por um conjunto de redes de computadores interconectadas por roteadores que utilizam o protocolo de transmissão TCP/IP. [F. red.: net. Tb. se diz rede.]"
} 
Nesse sentido, entendemos que compreender melhor o uso do chat, e particularmente do chat educacional, ${ }^{6}$ se constitui em um instrumento útil para nos apropriarmos de novas formas de organizar e administrar os relacionamentos interpessoais nesse novo contexto, ou seja, nos apropriamos de novos modos de interação social em um ambiente voltado à construção conjunta do conhecimento.

Pilkington et al. (1999) argumentam que, ao avaliar ambientes de aprendizagem, é preciso saber quais aspectos estão contribuindo para que ela de fato ocorra e elegem a interação verbal como um elemento crucial a ser investigado. Porém, apontam a dificuldade de identificar quais formas interativas são efetivas pelo fato de elas sempre estarem associadas a diferentes formas de gestão da sala de aula.

Para tentar superar a dificuldade, os autores explicitam a necessidade urgente de desenvolver métodos efetivos e confiáveis de análise do diálogo. Para tanto, propõem um modelo que separa a análise dos papéis e movimentos (fluxos interativos) das análises de conteúdo para, posteriormente, aplicar essas diferentes análises, em triangulação com medidas de desempenho, a uma variedade de situações educacionais.

Compartilhamos seu posicionamento tanto em relação ao destaque atribuído à importância do papel do diálogo em ambientes educacionais, quanto à proposta de metodologia de análise.

Ademais, considerando que um dos aspectos que desafia pesquisadores e profissionais da área da Educação a Distância $(\mathrm{EaD})$ é a busca de alternativas que venham a preencher a suposta lacuna afetiva (e comunicativa) do processo educacional em contextos digitais, propomo-nos descrever a constituição de um chat educacional em termos de conteúdo e papéis desempenhados pelos participantes. Assim, nossa análise será norteada pela:

\footnotetext{
${ }^{6}$ Optamos por manter o termo em Inglês, pois, além de já o termos incorporado a nosso léxico, ele se encontra registrado em dicionários da Língua Portuguesa, tais como o Aurélio - Século XXI. Em Português, o termo tem sido traduzido por bate-papo on-line, bate-papo virtual, papo on-line, papo virtual. Porém, destacamos o fato de o chat-educacional se configurar em gênero distinto do chat, de forma ampla, conforme proposto por Marcuschi (2002).
} 
a) identificação dos temas desenvolvidos neste espaço;

b) observação da forma pela qual eles são desenvolvidos;

c) identificação dos papéis desempenhados pelos participantes.

\section{Pressupostos Teóricos}

Concebemos a $\mathrm{EaD}$ como uma modalidade de ensino e não uma metodologia, baseando-se, portanto, em teorias e concepções que, em sua maioria, também sustentam a educação presencial. Assim, os estudos e cursos desenvolvidos pelos grupos de pesquisa que integramos, ${ }^{7}$ incluindo o presente trabalho, partem de uma concepção sócio-histórica do desenvolvimento humano, segundo a qual todas as funções psicológicas se desenvolvem na relação com o mundo, na interação do organismo com o meio físico e social em que vive, através da mediação de ferramentas auxiliares ou instrumentos psicológicos, conforme apontado por Vygotsky (1993).

Entender que a tecnologia é um produto sócio-cultural e que serve, além disso, como ferramenta física e simbólica para vincularse e compreender o mundo que nos rodeia, é uma derivação importante do pensamento de Vygotsky (LANTOLF, 2000; COLL et.al, 1986; WERSTCH, 1998), para quem "as tecnologias da comunicação são os utensílios com os quais o homem constrói realmente a representação, que mais tarde será incorporada mentalmente, se interiorizará" (VYGOTSKY, 1993).

As reflexões aqui desenvolvidas, no que se refere ao processo de aprendizagem, ao uso do meio digital para fins instrucionais

\footnotetext{
EDULANG - Grupo de pesquisa liderado pela $\operatorname{Prof}^{a} \operatorname{Dr}^{a}$ Heloisa Collins, que integra o projeto Lingüística Aplicada em Contexto Digital, inserido na interface das áreas da Lingüística Aplicada, Educação a Distância e Tecnologia Digital, desenvolvidos no âmbito do Programa de Pós-Graduação em Lingüística Aplicada e Estudos da Linguagem (LAEL), da PUC/SP (http:/ / lael.pucsp.br). TEED - Grupo de pesquisa em Tecnologia Educacional e Educação a Distância da Faculdade de Comunicação e Filosofia/PUCSP, liderado pela Prof ${ }^{a}$ Angelita Quevedo, formado por esquisadores dos departamentos de Português, Inglês, Francês, Lingüística e Fundamentos da Educação da PUCSP e um pesquisador da UNICSUL, foi oficializado em março de 2002 (http:/ / teed.modblog.com).
} 
e à própria mediação pedagógica, baseiam-se nas considerações acima e nos levam a partir do pressuposto de que os computadores oferecem ótimos recursos para abordagens educacionais que favorecem a construção do conhecimento, ${ }^{8}$ da autonomia e da autoformação do aprendente, no processo de aprendizagem (PRETI, 2000; SILVA LEITE; SILVA, 1998; VALENTE, 2000; ALMEIDA, 2000), desde que se observem as particularidades do novo contexto e que se faça um uso crítico das novas ferramentas disponíveis.

Conforme apontado por Khan (1997), Martins Fontes (2002) e Collins et al. (2003), entre outros, cursos que adotam essa perspectiva teórica buscam, em geral, promover a interação entre os participantes e, para tanto, utilizam designs e coursewares que prevêem o uso de diferentes ferramentas de comunicação como uma maneira de estimulá-la.

Embora o computador se revele um instrumento potencialmente importante para uso educacional, muitas questões ainda requerem estudos mais aprofundados para que o novo meio, de fato, seja utilizado como um instrumento que propicie a aprendizagem colaborativa.

Nesse sentido, um dos aspectos que têm sido foco de preocupação de estudiosos da área é o afetivo, uma vez que ao novo meio se atribui certa dificuldade na comunicação e estabelecimento de inter-relação entre os participantes. Esse fato levaria ao prejuízo do componente afetivo que, como se sabe, constitui um elemento fundamental para que o desenvolvimento cognitivo se realize.

Em um estudo voltado a cursos totalmente realizados a distância, Motteram (2001) defende que o uso de ferramentas de comunicação síncrona é mais efetivo para o aspecto social da educação, ao passo que ferramentas de comunicação assíncrona seriam mais adequadas ao tratamento de questões relacionadas ao aspecto acadêmico.

\footnotetext{
${ }^{8} \mathrm{O}$ termo construtivismo tem sido utilizado por estudiosos da EaD conforme apontado por Garrison (1993) para referir-se à concepção vygotskiana de aprendizagem. Para evitar o uso indiscriminado de um ou outro termo adotamos, para este estudo, o uso do termo sócio-histórico que se relaciona tanto com o interacionismo social, quanto com o sócio-construtivismo, cuja ênfase na teoria da atividade (LEONTIEV, 1979) é característica marcante.
} 
O autor salienta, ainda, que, embora a discussão de questões acadêmicas possa ser realizada em ambientes de comunicação síncrona, ela não atinge profundidade. Ele considera que a forma de encaminhamento das atividades possa ser uma das causas dessa situação.

Dedicados a estudar a qualidade da interação mediada por computador no contexto educacional, Garrison et al. (2000) propõem um modelo segundo o qual a aprendizagem resulta da interação de três componentes fundamentais, a saber: presença cognitiva, presença do professor e presença social. ${ }^{9}$

O primeiro elemento diz respeito à determinação do limite até o qual os participantes de determinada comunidade são capazes de construir sentido por meio de comunicação sustentada; o segundo inclui design e gerenciamento de seqüências didáticas, contemplando os temas específicos e facilitando a aprendizagem ativa. O último elemento, presença social, é definido como a habilidade de os aprendentes se projetarem social e emocionalmente em uma comunidade voltada ao ensino-aprendizagem.

Os autores afirmam que o último elemento tem por objetivo sustentar os objetivos cognitivos e afetivos da aprendizagem, sendo aqueles sustentados pela habilidade de estimular, sustentar e manter o pensamento crítico e esses pelo fato de tornarem as interações do grupo interessantes, envolventes e intrinsecamente compensadoras, levando, assim, ao aumento da integração acadêmica, social e institucional, o que, por sua vez, levará a um aumento na persistência dos alunos no curso.

Em estudo posterior, Rourke et al. (2001) dedicaram-se a averiguar um dos elementos do modelo, a presença social. Para tanto, subdividiram-na em três categorias: 1) afetiva, evidenciada por manifestações de humor, emoções e detalhes da vida pessoal; 2) interativa, evidenciada pela menção a falas anteriores, expressão de concordância e apreciação, apresentação de perguntas gerais; 3) coesiva, evidenciada pelo uso de vocativos, manifestação de inclusão em relação ao grupo (uso de termos como nós, nosso, nosso grupo) e realização da função fática propriamente dita, como saudação e despedida.

\footnotetext{
${ }^{9}$ Tradução nossa. No original, esses conceitos foram designados por cognitive presence, teaching presence e social presence, respectivamente.
} 
Collins et al. (2003b) constataram a validade dessas categorias em um chat educacional e destacaram a importância da presença social para a manutenção de um ambiente acolhedor, elemento fundamental para estimular a participação discente.

Ao analisarmos as ações docentes em diferentes espaços interacionais no contexto digital (GERALDINI, 2003), identificamos a existência de uma inter-relação entre as esferas ${ }^{10}$ social e de conteúdo. A configuração das interações então analisadas nos permite sugerir que aquela pode prescindir dessa. Já o contrário não foi observado. Nesse sentido, reiteramos o posicionamento dos autores supra citados, que evidencia a importância da dimensão social no contexto digital de ensino.

Para que possamos propor uma reflexão mais completa sobre a questão interacional, aos elementos acima evocados, é necessário acrescentar aspectos relativos ao meio e sua implicação no estabelecimento de uma configuração específica da comunicação no contexto digital.

Vários autores argumentam, por exemplo, que o papel do professor on-line é diferente do desempenhado pelo professor presencial (PRETI, 2000), inclusive em função das características do meio que prevê uma interação mais flexível, de natureza conversacional, em que o papel da linguagem é fundamental (MOTTERAM, 2001; MARCUSCHI, 2002).

Ao aprofundar a discussão do aspecto interacional da Comunicação Mediada por Computador (CMC), citamos Hilgert, que se insere na linha de autores que consideram que, em um chat, a interação apresenta algumas características da interação face a face, uma vez que os interlocutores " [...] sentem-se falando, mas, pelas especificidades do meio que os põe em contato, são obrigados a escrever suas mensagens, ou seja, interagem, construindo um texto 'falado' por escrito" (HILGERT, 2000, p. 17).

Jonsson (2002) também argumenta que, em função de seu caráter síncrono, o chat simula uma relação face a face. A este

\footnotetext{
${ }^{10}$ A atuação docente foi caracterizada a partir de ações docentes, organizadas em esferas ou dimensões. Foram identificadas as seguintes esferas: organização do trabalho, conteúdo, técnica e social.
} 
posicionamento credita-se a abordagem comumente adotada para a análise de chats que focaliza, de alguma forma, a relação entre a língua falada e a língua escrita.

Nesse sentido, Hilgert (2000) discute as estratégias de construção do texto da conversação na internet à luz do que já se estudou e escreveu sobre a construção da conversação face a face. $\mathrm{O}$ autor defende que a escrita, juntamente com outras condições de produção da comunicação na rede, vai imprimir características próprias a este tipo de interação.

Desse modo, em sua abordagem, ele se propõe a estabelecer uma relação entre essas duas modalidades discursivas, em vez de contrapor fala e escrita. Defensores dessa corrente chegam a caracterizar esse gênero lingüístico como um "oral grafado" (PALMA, 2003, comunicação pessoal).

É nessa perspectiva que Hilgert (2000) aborda o sistema de turnos conversacionais, argumentando que, por ser essencial e intensamente dialogal, a conversação na internet pode ser concebida como fala e se desenvolve por meio da alternância de turnos. Salienta, porém, que os turnos são mais curtos do que na conversação face a face e se constituem, basicamente, de pares adjacentes, os quais, por sua vez, tendem à objetividade e não favorecem divagações que poderiam se estender em turnos mais longos, levando, assim, à redução do grau de dialogicidade.

Já na interação face a face, diversamente da internet, a relação assimétrica entre interlocutores pode provocar turnos mais longos. Alguém que manifesta mais conhecimento sobre o tema em pauta acaba impondo certa autoridade sobre os demais que, quase inconscientemente, lhe outorgam mais tempo de fala. Do ponto de vista das relações de poder, "os que estão em uma posição inferior têm menos turnos e ficam mais silenciosos" (MURRAY, 1989, p. 336).

Considerando os aspectos acima expostos, buscaremos apontar eventuais ajustes a esses conceitos com o intuito de contribuir para sua aplicação ao contexto interacional digital. 


\section{Metodologia}

\subsection{Seleção do corpus}

O corpus analisado neste trabalho é um chat de alunos, exclusivamente, realizado no módulo de Leitura Instrumental nível II, do curso de Formação continuada em Língua Inglesa para professores da rede estadual de São Paulo, ${ }^{11}$ ministrado no período de novembro de 2000 a fevereiro de 2001.

O curso foi desenvolvido para disponibilização no programa de autoria WebCT, versão 1.3. Esse programa oferece diferentes ferramentas para a realização de cursos, o que se traduz na existência de certo grau de liberdade na concepção de diferentes designs, a partir dos objetivos visados. Assim, dentre várias possibilidades, os designers selecionaram os recursos considerados mais adequados aos propósitos do curso, conforme segue: ${ }^{12}$ ferramentas de produção, de estudo, de avaliação e de comunicação.

Por razões de delimitação do foco, consideraremos, aqui, apenas uma das ferramentas de comunicação: o chat (comunicação síncrona), sendo que, para este trabalho, o recorte feito contemplou um encontro síncrono (de um total de onze realizados neste módulo, durante o período de sua duração).

Conforme apresentado na discussão teórica, em função dos pressupostos subjacentes ao design desse curso, diversos tipos de atividades foram elaborados de forma a propiciar a interação entre os participantes (alunos e professores) e o material.

\footnotetext{
${ }^{11}$ Este curso foi elaborado no âmbito de uma parceria estabelecida entre o programa de Lingüística Aplicada e Estudos da Linguagem (LAEL) da PUC/ SP e a Cultura Inglesa de São Paulo para o desenvolvimento de um programa de formação continuada para os professores de Inglês da rede pública de ensino e apresentou a seguinte composição: dois módulos presenciais, destinados à produção oral, com aulas quinzenais, ministradas aos sábados, em Araraquara, por um professor da Cultura Inglesa e/ou Lael e três módulos a distância, sendo dois destinados à compreensão escrita, leitura instrumental, e um à compreensão oral.

${ }^{12}$ Para uma descrição completa da estrutura do curso, consultar Carelli (2003) ou http://lael.pucsp.br/.
} 
Assim, sua estrutura previa atividades individuais e em grupos, o que pressupôs o estabelecimento de interação entre os alunos, sem a presença do professor (chats), para o preparo de atividades, tais como a discussão sobre o tema de um texto lido e subseqüente elaboração de síntese a ser apresentada para os demais participantes do curso no Bulletin Board (BB). ${ }^{1}$

Dessa forma, o encontro aqui analisado foi marcado pelo grupo, conforme proposto na orientação das atividades do curso: a partir da leitura de um texto sobre o tema, What makes a good school, os alunos deveriam discutir conceitos e propostas para, então, elaborar conjuntamente um resumo a ser posteriormente enviado ao Bulletin Board. Em um segundo momento, todo o grupo se apropriaria dos trabalhos das demais equipes e a discussão seria desenvolvida no próprio BB.

Duas razões justificam a escolha desse encontro para a presente análise: inicialmente, o fato de as alunas terem marcado, mantido e realizado o encontro (o que não ocorreu com todos os sub-grupos) e de terem utilizado a língua inglesa para sua comunicação durante a totalidade do tempo do encontro. Em segundo lugar, pelo fato de considerar esta análise como complementar à realizada em nossa pesquisa de doutoramento (GERALDINI, 2003), cujo foco se restringiu à atuação docente.

Como veremos a seguir, grande parte do tempo foi dedicada à discussão do tema do texto lido e à organização da atividade a ser realizada na seqüência (summary). Identificamos, igualmente, evidências de construção conjunta de conhecimento, conforme já apontado.

\subsection{Procedimentos de análise}

Inicialmente, foram identificados os temas ${ }^{14}$ abordados nesse encontro (ver quadro 1 e figura 1, item 3).

\footnotetext{
$\overline{{ }^{13} \text { Fórum. Ferramenta por intermédio da qual foi viabilizada a comunicação }}$ assíncrona.

${ }^{14}$ Estamos utilizando os termos tópicos e temas indistintamente. Quando se considera a análise de conteúdos, fala-se em temas. Por outro lado, na perspectiva
} 
Em seguida, de acordo com o procedimento proposto por Miles \& Hubermann (1984), esses temas foram agrupados em categorias que correspondem a dimensões (ou esferas) constituintes desse espaço interacional, a saber: da organização do trabalho, do conteúdo, social e técnica (ver quadro 2 e figura 2 , item 3 ).

A terceira etapa teve por objetivo detalhar o quadro temático desenvolvido. Foram identificados a inserção dos temas e seu desenrolar ao longo do encontro. Para tanto, adotamos um posicionamento teórico que reúne grande parte dos pesquisadores dedicados seja a estudos da linguagem, especialmente da análise conversacional e análise do discurso, seja da $\mathrm{EaD}$, segundo o qual a comunicação síncrona no ambiente digital apresenta algumas características da interação face a face (JONSSON, 2002; MARCUSCHI, 2002; HILGERT, 2000, entre outros).

Assim, para sua análise, o chat foi concebido como um Discurso Interativo Dialogado (BRONCKART, 1999). Este tipo de discurso se constitui por uma (ou mais) seqüência(s) dialogal(ais), que se estrutura(m) em turnos de fala, assumidos pelos agentes-produtores de uma determinada interação verbal (nos discursos interativos primários) ou atribuídos a personagens no âmbito de um discurso maior (discursos interativos secundários).

A seqüência dialogal apresenta as seguintes fases:

- abertura $=$ os interactantes entram em contato observando regras sócio-comunicativas que variam, inclusive, em função da cultura em que os agentes enunciadores se inserem;

- operações transacionais, nas quais o conteúdo temático da interação é co-construído;

- encerramento = fim da interação.

da análise da conversação, é muito freqüente o uso do termo tópico e derivados envolvendo, videntemente, vários níveis de recortes. Assim, partindo-se do nível mais baixo em um escala crescente, tem-se segmentos tópicos, subtópicos, quadro tópico e supertópico (KOCH, 1995, p. 72). Já Bronckart (1999), em seu modelo de análise do discurso, utiliza a expressão conteúdo temático para significar "o conjunto das informações nele explicitamente apresentadas, isto é, que são traduzidas no texto pelas unidades declarativas da língua natural utilizada" (BRONCKART, 1999, p. 97). 
As fases são decompostas em trocas, compostas de intervenções (turnos de fala) e, em um outro nível, decompostas em enunciados que realizam um ato de fala.

Para os objetivos deste trabalho, identificação dos temas e acompanhamento de seu desenvolvimento (fluxo do conteúdo temático), foi possível restringir a análise ao primeiro nível proposto pelo autor (abertura, fase transacional e fechamento). ${ }^{15}$ Essa etapa encontra-se apresentada nas figuras 3 e 4 , respectivamente, do item 3 . Não foram identificados os atos de fala de cada participante, pelo fato de este detalhamento fugir ao escopo desta análise.

A quarta e última etapa foi proposta com o objetivo de explorar esse quadro em sua dimensão interacional. Assim, foram identificados os fluxos interativos estabelecidos entre os participantes (cf. quadro 5, item 3).

\section{Análise e Discussão dos Resultados}

O quadro 1, a seguir, apresenta os temas abordados pelos participantes e respectivo número de ocorrências.

\footnotetext{
${ }^{15}$ Em estudo anterior (GERALDINI, 2003), o aprofundamento da análise se revelou profícuo e adequado para a exploração dos aspectos lingüisticodiscursivos da situação interacional. Para explorar a interação na sala de digital, nossa análise se desenvolveu nos três níveis propostos por este modelo, tendo chegado a identificar os atos de fala da professora em questão. Para outros exemplos de análise interacional a partir do modelo bronckartiano de análise do discurso, consultar os trabalhos de Piesco (1999) e Melão (2001).
} 
Quadro 1 - Temas abordados e Número de ocorrências ${ }^{16}$

\begin{tabular}{|l|c|}
\hline \multicolumn{1}{|c|}{ Temas } & \multicolumn{1}{|c|}{$\begin{array}{c}\text { Número de } \\
\text { Ocorrências }\end{array}$} \\
\hline $\begin{array}{l}\text { 1. Texto (sobre o tema What makes a good } \\
\text { school }\end{array}$ & 27 \\
$\begin{array}{l}\text { 2. Summary (atividade a ser realizada e } \\
\text { entregue pelo grupo) }\end{array}$ & 14 \\
3. Chuva & 5 \\
4. Horário das aulas presenciais & 3 \\
5. Filhos / família & 5 \\
6. Língua (vocabulário) & 7 \\
7. Problemas técnicos & 5 \\
8. Chat do dia seguinte & 4 \\
\hline \hline Total de ocorrências dos temas & $\mathbf{7 0}$ \\
\hline $\begin{array}{l}\text { Demais intervenções } \\
\text { (caráter coesivo - função fática) }\end{array}$ & 38 \\
\hline \hline Total geral de turnos do encontro & $\mathbf{1 0 8}$ \\
\hline
\end{tabular}

Para uma melhor visualização, apresentamos as informações do quadro 1, acima, em forma gráfica, na figura 1, a seguir:

\footnotetext{
${ }^{16}$ Número de vezes que o tema foi abordado.

${ }^{17}$ A titulo de exemplo, apresentamos os trechos a seguir, correspondentes aos turnos Nos. 10 "Paula... Where are you my dear?', 11 “' $i$ here." e 31 "Did you read what i wrote?"
} 


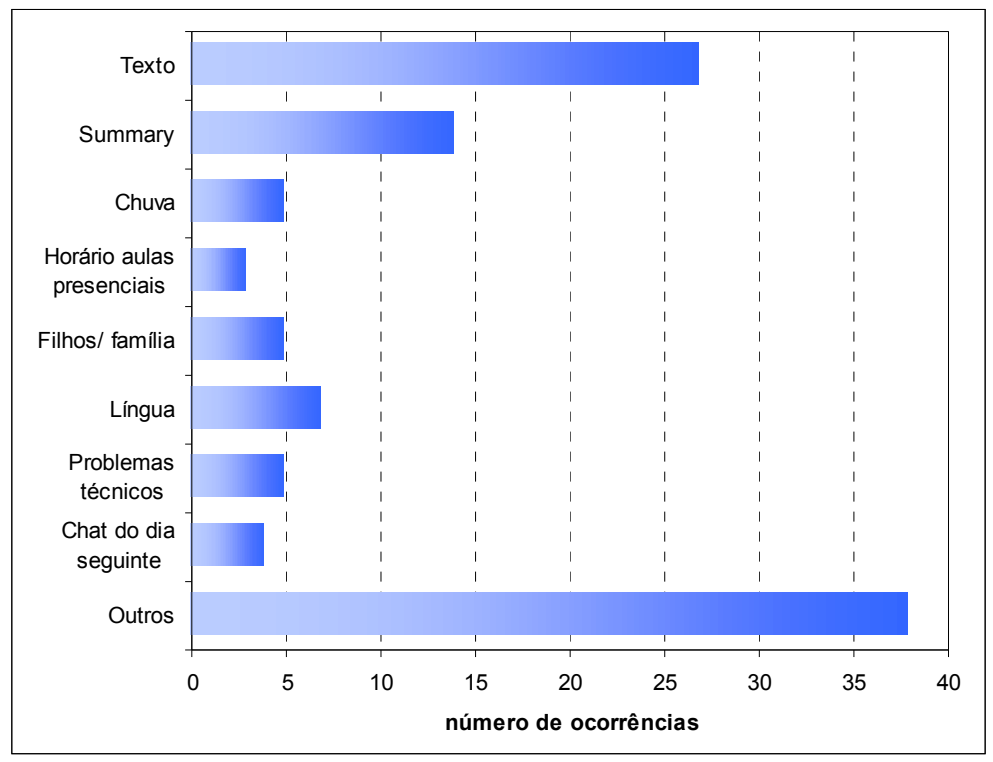

Figura 1 - Temas abordados e Número de ocorrências

Esta primeira aproximação dos temas abordados no chat revela que seu objetivo principal (conforme previsto pela atividade da unidade tratada naquele momento do curso, que demandava a discussão do texto) foi mantido, uma vez que os temas relativos ao conteúdo (1 e 2) foram preponderantes, não só em termos de número de ocorrências como também em duração (este dado será apresentado na figura 2, a seguir). Cabe lembrar que, apesar do grande número de ocorrências de "outros", não se pode considerá-lo como tema, uma vez que compreende, basicamente, intervenções de caráter coesivo, correspondendo à função comunicacional fática.

Temas circunstanciais, relativos a questões contextuais se apresentaram de forma esparsa e pontual (temas 3, 4, 7 e 8).

O tema número 6 (língua) apresentou uma particularidade, proveniente do meio: três de suas ocorrências se referiram ao vocabulário do texto (a), e quatro a um ruído comunicativo (b), provocado por um erro de digitação que não foi identificado como erro por nenhuma das participantes, conforme ilustram os trechos a seguir: 
(a)

What' the meaning of' NEW AGEY?

yes, Paulinha ${ }^{18}$. They are evaluated by some people who judge.

I agree Paulinha.

I agree with you, Paulinha. Jaci, what is that?

tHis word appeared in the text.

It means Nova ERA?

Sorry, I don't have the text in my hands now. I'm talking about what I can remember.

Probably, Jaci.

it would be a name of a modern method. Nova era is New age! New agey can make alusão a Nova Era.

Mary, the text is here: "It sounds New Agey but students understand"

Oh, I see. It really is a new way of thinking, teaching and learning.

(b)

[...] My fiancé is Ok, Do you believe that yesterday he didn' saty with me???

Bye Mary. dream with the angels see you tomorrow.

Before leaving: what's the meaning of saty?

What' s saty, Jaci?

Paula, I need to go now too because I have to prepare my classes for tomorrow. See you, good night and you know that I like you too (and the babies too) KISSES

I don' t know.....

Mary where have you see this word?

\footnotetext{
${ }^{18}$ Apelido criado por esta autora, a partir do nome fictício adotado para os participantes desse estudo. Esse procedimento foi adotado com a intenção de manter a fidelidade ao texto original, uma vez que as participantes se designavam por apelidos. Isso foi feito em todas as seqüências em que há transcrição de trechos do texto original.
} 
O quadro 2 apresenta a categorização dos temas, bem como a descrição de cada categoria.

Quadro 2 - Categorização dos temas

\begin{tabular}{|c|c|}
\hline Esfera & $\begin{array}{c}\mathbf{N}^{\circ} \cdot \text { de } \\
\text { ocorrências }\end{array}$ \\
\hline $\begin{array}{c}\text { 1. da Organização do trabalho (rotina, horários dos } \\
\text { encontros, prazos para a realização de atividades, } \\
\text { etc) }\end{array}$ & 10 \\
\hline $\begin{array}{c}\text { 2. do Conteúdo (conteúdo de língua, estratégias de } \\
\text { leitura e temas presentes nos textos do curso, }\end{array}$ & 58 \\
\hline $\begin{array}{c}\text { 3. Social ( compreende as dimensões afetiva e coesiva - } \\
\text { fática) }\end{array}$ & 35 \\
\hline $\begin{array}{c}\text { 4. Técnica (instruções referentes ao uso do meio, } \\
\text { problemas técnicos e questões práticas) }\end{array}$ & 5 \\
\hline \hline Total & 108 \\
\hline
\end{tabular}

Apresentamos, abaixo, um exemplo ilustrativo do conteúdo de cada esfera.

A esfera da Organização do trabalho, como o próprio nome sugere, refere-se a questões organizacionais, conforme ilustram os trechos abaixo, extraídos dos turnos 47 e 87 , respectivamente:

- I think we have good ideas about the text. By the way do you know that we have a chat with Roberta ${ }^{19}$ tomorrow???

- Because I think it'l be impossible to join everybody in our group

A esfera do conteúdo refere-se, naturalmente, a questões de conteúdo do curso, a saber, textos lidos, estratégias de leitura e questões de natureza lingüística, conforme ilustram os trechos abaixo, extraídos dos turnos 14 e 73 respectivamente:

${ }^{19}$ Nome fictício da professora do grupo. 
- The thing I thought the most interesting is what the director said at the end of the text: the goal is to give the students tools to work with.

- What' the meaning of 'NEW AGEY?

A esfera social refere-se tanto a questões de natureza afetiva e pessoal, quanto pragmática (contextuais) e de natureza fática (ou coesiva), como ilustram os trechos abaixo extraídos dos turnos 13 e 31 respectivamente:

- Mary, you told me that you'l be able to come here only at 10:00. Where is the litlle angel(your son)?

- Did you read what i wrote?

A última esfera, técnica, compreende desde questões relativas ao uso do meio até questões circunstanciais e contextuais, conforme ilustram os trechos abaixo, extraídos dos turnos 8 e 28 respectivamente:

- Paulinha, how are you? I have a suggestion for you: leave the room and come back again because you may have problems being twice.

- Now it' raining here... maybe i'l 1 have some problems ....

Para uma melhor visualização tanto da dimensão ocupada por cada esfera, quanto da configuração global do encontro, apresentamos as informações do quadro 2, acima, em forma gráfica, na figura 2 , a seguir: 


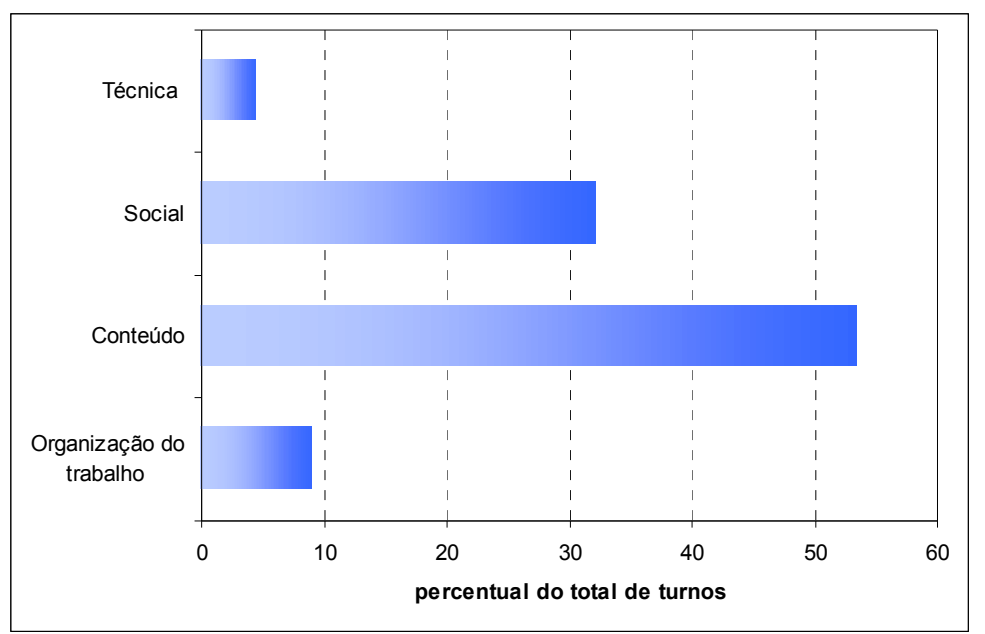

Figura 2 - Categorização dos temas

Como se pode observar, a esfera do conteúdo foi predominante neste encontro, seguida da esfera social. Na seqüência, tivemos a esfera da organização do trabalho e, em último lugar, a esfera técnica.

Identificamos, aqui, os três elementos fundamentais para a promoção de aprendizagem, de acordo com o modelo proposto por Anderson et al. (2001), presença cognitiva (aqui correspondendo ao conteúdo tratado), presença de ensino ou do professor (aqui representado pela líder do grupo que direciona o fluxo interacional, como se verá na figura 4, a seguir) e presença social ( correspondendo à categoria social, conforme apresentado no quadro 3, acima).

Esses resultados divergem dos apresentados por Marcuschi (2002, p. 33) no que se refere ao tempo gasto com a administração de problemas operacionais, quedas e lentidões das máquinas. O autor verificou um percentual equivalente a $20 \%$ do tempo total dos encontros estudados dedicados a essas questões.

Diferem, igualmente, do apontamento feito por Motteram (2001), segundo o qual haveria maior eficácia do uso de ferramentas assíncronas para se abordar questões de natureza acadêmica e síncronas para questões de ordem social, uma vez que no presente estudo houve percentual significativo de tratamento de questões das duas esferas: acadêmica (ou de conteúdo) e social. 
A figura 3, abaixo, corresponde à terceira etapa analítica, destinada a explorar a inserção e desenvolvimento dos temas.

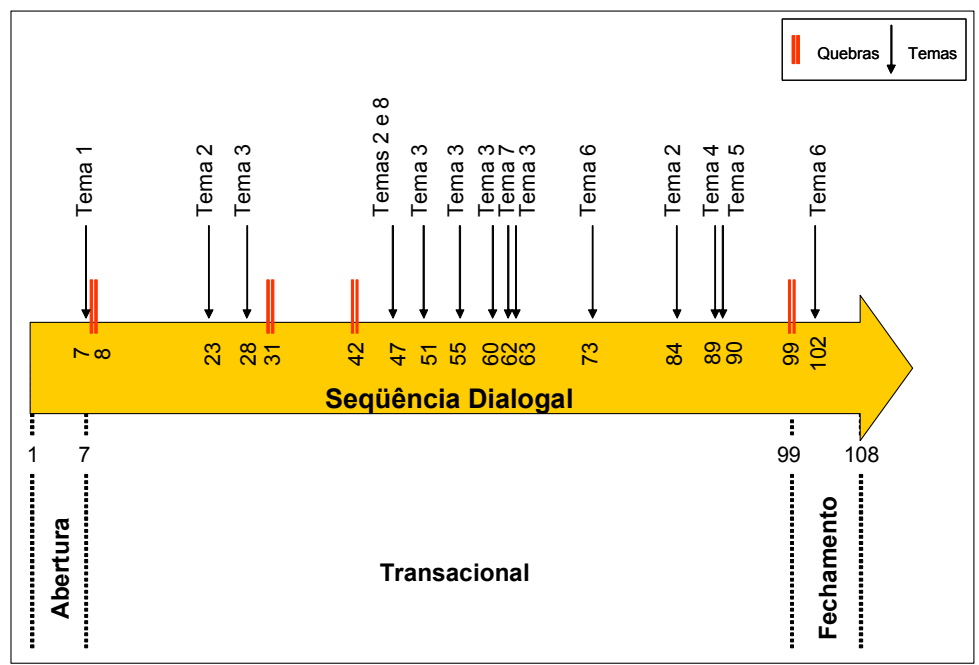

Figura 3 - Inserção dos temas

Como se pode observar, o evento comunicativo analisado apresenta as fases de abertura, transacional e fechamento, propostas por Bronckart (1999), claramente demarcadas, conforme apontado na figura 4 , acima.

Observe-se que a fase transacional, em que ocorre de fato a troca de informações, as negociações, enfim, o desenvolvimento dos temas propostos para o encontro, ocupa a maior parte do evento comunicativo.

No que se refere à inserção dos temas, temos a considerar que ela sempre ocorre sob a forma de uma interrupção, já que o contexto digital não possibilita a realização de um sistema de alternância de turnos similar ao característico da interação face a face, em que um participante fala por vez ou, no máximo, há sobreposição de falas (em geral, breves e pontuais).

Porém, nem toda interrupção se transforma posteriormente em tema (este aspecto pode ser observado na figura 3, acima). Isso ocorre nos turnos 8, 31, 42 e 99 (conforme indica a barra dupla) que desempenham uma função fática ou coesiva, conforme 
ilustram os trechos abaixo correspondentes aos turnos 31e 42, respectivamente:

- "Did you read what i wrote? (turno 31)

- "And my question??? Answer or I'l 1 cry...."

Um último aspecto a ser observado em relação a essa questão é o fato de o tema ser, de fato, iniciado, no mínimo dois turnos após ter sido anunciado pelo participante. Este fato pode ser atribuído às características do contexto, mais especificamente a restrições de natureza técnica, uma vez que há um intervalo de tempo, destinado ao processamento da informação, entre a inserção da informação por um participante e sua "publicação" (ou divulgação, exibição) da na tela dos demais participantes.

A figura 4, abaixo, detalha o desenvolvimento dos temas inseridos.

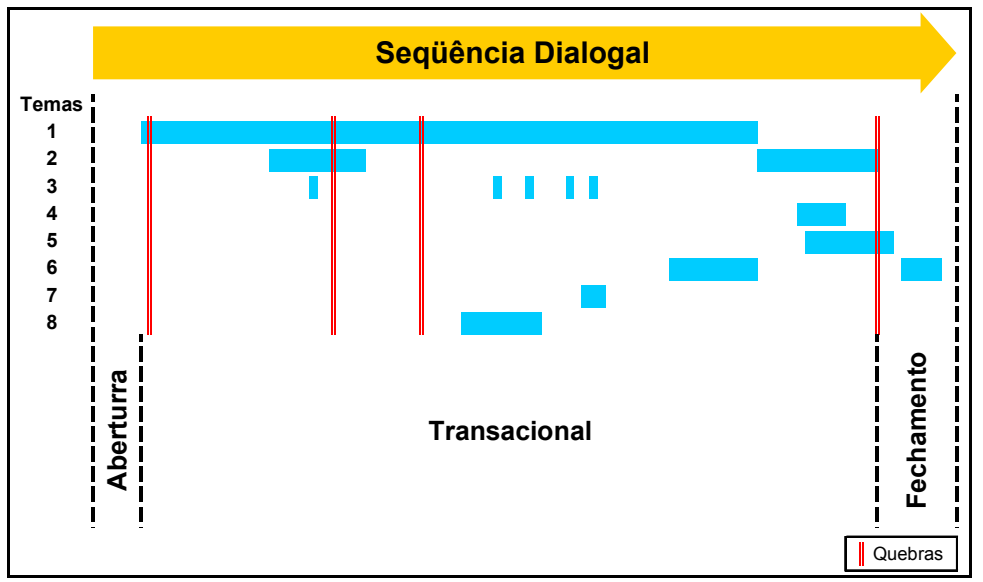

Figura 4 - Desenvolvimento dos temas

Observe-se que o tema 1 (Texto) ocupa quase a totalidade da fase transacional. Cabe destacar que ele se mantém, apesar de todas as interrupções ocorridas, algumas das quais introduziram outros temas, que foram conduzidos simultaneamente, durante algum tempo. Isso ocorre com os temas $2,4,5$, 6 e 8 . 
Como se verá na figura 5, a seguir, ele é introduzido e monitorado por uma das alunas (este fato contribuiu para nossa interpretação segundo a qual ela assume o papel de mediadora nesse encontro).

Os temas 6 e 8 aparecem de forma breve, e são desenvolvidos simultaneamente ao tema 1 (o tema 6 parcialmente, apenas). Eles abordam questões do curso, sendo que o tema 6 , referente à língua (portanto, relacionado ao conteúdo do curso) reaparece. Isso não ocorre com os temas que não estão diretamente relacionados ao conteúdo do curso (temas 3, 4, 5 e 7).

O tema 3 (chuva) atraiu nossa atenção pelo fato de ter aparecido de forma pontual e foi desenvolvido como um elemento circunstancial, coerente com sua natureza. A esse respeito, gostaríamos de manifestar nossa surpresa (positiva) ao constatarmos que, embora fosse um elemento potencialmente gerador de dispersão, esse fenômeno não se realizou. Atribuímos esse fato a uma possível maturidade e motivação das participantes, bem como a uma clara definição dos objetivos do encontro.

Para finalizar a discussão desse aspecto, salientamos que, em função das características da configuração comunicativa aqui observadas, a habilidade de operação do participante constitui um elemento fundamental para assegurar uma participação de qualidade, já que é possível manter simultaneamente diálogos sobre temas centrais e paralelos.

Nesse sentido, apontamos como igualmente necessária certa familiarização com o gênero chat, posto que o sentido de um turno depende inteiramente da relação com turnos anteriores e subseqüentes, embora eles não se apresentem de forma contígua, como pares adjacentes. Pelo contrário, no contexto digital a defasagem é característica intrínseca do sistema de turnos.

A última figura (figura 5) ilustra o fluxo interativo constituído pela participação das alunas no chat. 


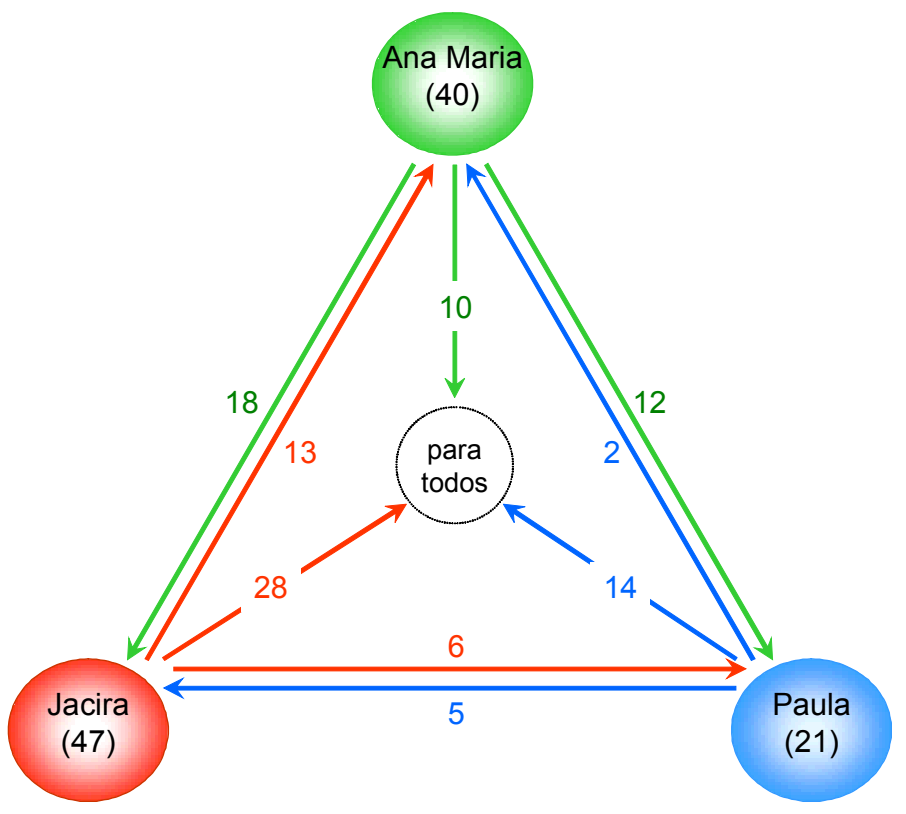

Figura 5 - Fluxo Interativo

De um total de 108 turnos empreendidos neste encontro, Jacira é responsável por 47, Ana Maria por 40 e Paula por 21. Em termos quantitativos, há relativo equilíbrio entre a quantidade de turnos empreendidos pelas duas primeiras alunas e evidente desequilíbrio em relação à terceira. Do ponto de vista das relações de poder, pode-se vislumbrar a existência de uma certa hierarquia entre as participantes.

No entanto, o maior número de turnos realizado por Jacira aliado à qualidade (conteúdo) dos mesmos, nos levou a considerar que a aluna assume o papel de mediadora do grupo, agindo como professora, ao dirigir as discussões, ao lembrar as demais colegas de questões relativas ao curso (como as orientações para a realização de atividades), como se pode atestar nos trechos abaixo, extraídos dos turnos 7, 9, 23 e , 47, respectivamente:

- "Let's start our discussion? First I' like to say that I think our text very interesting." 
- "I think that one school like this would be very good here, but our system....Tell what you liked most in the text?"

- "Girls I'm taking notes about your opinions to do the summary, ok?"

- "I think we have good ideas about the text. By the way do you know that we have a chat with Roberta $^{20}$ tomorrow???"

Vale salientar que as demais colegas demonstram aceitação de seu papel de orientadora, conforme ilustram os trechos abaixo, extraídos dos turnos 50 e 85, de Ana Maria, 56 e 98 de Paula, respectivamente:

- "Yes, Jaci. I know about the chat. Are you be there?"

- "Sure, Jaci. I'd like to ask you something: are we supposed to write a summary by ourselves?"

- "what time will be the chat tomorrow? AND..about the five paragraph? i didn't understand it."

- "ok, Jaci! After our meeing, i will send you some ideas about the summary. May I? How are your fiancé?"

Ainda em termos quantitativos, dos 47 turnos realizados por Jacira, 28 são dirigidos a todos ( ao grupo), o que vem confirmar nossa interpretação sobre seu papel de mediadora.

Esse dado nos leva a considerar a importância da figura do líder para a comunicação em grupo, conforme defendido por Dimbleby \& Burton (1985), além de reiterar a importância da presença do professor para a construção conjunta de conhecimento em interações mediadas pelo computador, no contexto educacional

\footnotetext{
${ }^{20}$ Nome da professora, também fictício.
} 
(Anderson et al. 2001). Assim, na ausência da professora, uma das participantes presentes desempenha este papel, assumindo funções de mediadora.

\section{Considerações Finais}

Este estudo teve por objetivo contribuir para a construção de um modelo de análise de chats educacionais. Para tanto, um encontro foi descrito e analisado em termos de conteúdo e participação dos envolvidos.

Questões relativas aos padrões interacionais, específicas do meio, foram apontadas para posterior consideração em futuras análises, pois, conforme se pode verificar na discussão teórica, hoje já há algum conhecimento acumulado na área, a partir do qual modelos de análise coerentes com as especificidades do novo meio podem desenvolvidos.

Nesse sentido destacamos duas questões: inicialmente, adotamos a classificação do chat educacional (MARCUSCHI, 2002) como um gênero emergente, originado a partir do chat ou bate-papo virtual, ou seja, já teríamos o surgimento de um gênero dentro de outro gênero. Como os gêneros relacionam-se à sistematização ou padronização de práticas sociais (BAKHTIN, 1929), vemos aí a constituição de um novo enquadre para a "sala de aula" ou, melhor dizendo, de "momentos de construção compartilhada de conhecimento".

Em segundo lugar, o sistema de alternância de turnos de fala e de pares adjacentes deve ser redimensionado para o contexto digital, inclusive em decorrência de restrições de natureza técnica. Nesse sentido, a exploração do gênero chat educacional pode ser útil para preparar futuros usuários dessa ferramenta, uma vez que o desconhecimento de suas características próprias pode levar a um prejuízo do desempenho dos envolvidos (conforme observado por Collins et al., 2003).

Finalmente, a título de conclusão, para retomarmos a pergunta-título deste trabalho: "afinal, que espaço é esse?", recuperamos a consideração feita por Pilkington et al. (1999) que transformamos em pergunta: quais aspectos do meio contribuem para a aprendizagem? 
Longe de propormos respostas completas e fechadas, consideramos que a discussão aqui apresentada nos dá algumas pistas. Uma delas sugere a necessidade de um chat educacional, de fato voltado à aprendizagem e à construção conjunta de conhecimento, reunir elementos de ordem cognitiva e afetiva, consideração que reitera a pertinência dos elementos postulados por Anderson et al. (2001). Ficam igualmente colocadas a importância de um ambiente afetuoso e colaborativo, a atuação de um interlocutor privilegiado, bem como uma definição clara dos objetivos do encontro.

Esses elementos só podem se configurar dessa forma, acreditamos, na conjunção de um design de curso de qualidade e de participantes (professores e alunos) engajados e dispostos a transformar esse espaço em uma atividade essencialmente humana: o ensino.

\section{Referências Bibliográficas}

ALMEIDA, M. E. B. de. O Computador na escola: contextualizando a formação de professores: praticar a teoria, refletir a prática. 2000. Tese (Doutorado em Educação: Supervisão e Currículo) - Pontifícia Universidade Católica de São Paulo, São Paulo.

ANDERSON, T.; ROURKE, L.; GARRISON, D. R.; ARCHER, W. 2001. Assessing teaching presence in a computer conferencing context. Journal of Asynchronous Learning Networks, v. 5, n. 2, set. 2001. Disponível em: <http://www.sloan-c.org/publications/jaln/v5n2/ index.asp $>$. Vários acessos.

BAKHTIN, M. Marxismo e Filosofia da Linguagem. São Paulo: Hucitec, 1929.

BELLONI, M. L. Educação a distância. Campinas: Autores Associados, 1999.

BRASIL. Ministério da Educação e Cultura. Parâmetros Curriculares Nacionais. Terceiro e Quarto Ciclos do Ensino Fundamental introdução. 1998. 
BRONCKART, Jean-Paul. Atividade de linguagem, textos e discursos - por um interacionismo socio-discursivo. São Paulo: Educ, 1999.

BUZATO, M. O letramento eletrônico e o uso de computadores no ensino de língua estrangeira: contribuições para a formação de professores. Campinas: UNICAMP, 2001.

CARELLI, I. M. Estudar on-line: análise de curso para professores de inglês na perspectiva da teoria da atividade. 2003. Tese (Doutorado em Lingüística Aplicada ao Ensino de Línguas) - Pontifícia Universidade Católica de São Paulo, São Paulo.

CARNEIRO, R. Informática na Educação: representações sociais no cotidiano. São Paulo: Cortez, 2002. (Coleção Questões da nossa época, 96).

CELANI, M. A. A. 1984. Is there too much concern for the cognitive in our teacher training programs? In: ENCONTRO NACIONAL DE PROFESSORES UNIVERSITÁRIOS DE LÍNGUA INGLESA - ENPUli, 5., 1983, São Paulo. Anais... São Paulo: PUCSP, 1984.

COLL, C. et al. (Orgs.) Desenvolvimento psicológico e educação. Psicologia da educação. Porto Alegre: Artes Médicas, 1986.

COLlinS, Heloísa; FERREIRA, Anise (Eds.; Orgs.) Relatos de experiência de Ensino e Aprendizagem de Línguas na Internet. Campinas: Mercado de Letras, 2003a.

COLLINS, Heloisa; FERREIRA, A.; MAZZILLO, T.; GERVAI, S.; LANG, E.; SANTI, L. C.; LEITES, S.; MELLO FILHO, J. C.. Por que é difícil participar de chats? Revista Brasileira de Linguística Aplicada, Belo Horizonte, v. 3, n. 2, p. 41-71, 2003b.

D'AMBRÓSIO, U. Educação para uma sociedade em transição. Campinas: Papirus, 1999. (Coleção Papirus Educação)

DELORS, J. et al. Educação: um tesouro a descobrir. Relatório para a Unesco da Comissão Internacional sobre Educação para o século XXI. São Paulo: Cortez, 1998. 
DIMBLEBY, R.; BURTON, G. Mais do que palavras. Uma introdução à teoria da comunicação. São Paulo: Summus, 1985.

FERREIRA, A.; COLlins, H. (Orgs.). Relatos de ensino e aprendizagem de línguas na internet. Campinas: Mercado de Letras, 2004. v. 1

FREIRE, P. [1992] Educação como prática da liberdade. 23. ed. São Paulo: Paz e Terra., 1999.

FREIRE, M.; STAA, B.; MONTANHEZ, E. B. A.; CARELLI, I. M.; WADT, M. P. S.; SPRENGER, T. M.; SABBAG, M. C.; Shimazumi, M.; MARTINS, L. R.; WEYERBACH, S. H. [2003] Roteiro para avaliação de cursos on-line de idiomas. In: FERREIRA, A.; COLLINS, H. (Org.) Relatos de ensino e aprendizagem de línguas na internet. Campinas: Mercado de Letras, 2004. v. 1.

FREIRE, M. M.; RAMOS, R. C. G. Buscando parâmetros para a formação do professor para o contexto digital. In: ENCONTRO NACIONAL DE PROFESSORES UNIVERSITÁRIOS DE LÍNGUA INGLESA - ENPULI, 16., 2001, Londrina. Caderno de Resumos... Londrina: UEL, 2001. p. 31.

GARRISON, D. R. [1993] Quality and access in distance education: theoretical considerations. In: KEGAN, D. (Ed.) Theoretical Principles of Distance Education. London: Routledge, 1996.

.; ANDERSON, T.; ARCHER, W. Critical thinking in a textbased environment: computer conferencing in higher education. Internet and Higher Education, v. 11, n. 2, p. 1-14, 2000.

GERALDINI, A. F. S. Docência no ambiente digital: ações e reflexão. 2003. Tese (Doutorado em Lingüística Aplicada ao Ensino de Línguas) - Pontifícia Universidade Católica de São Paulo, São Paulo.

GÓMEZ, A. P. O pensamento prático do professor - a formação do professor como profissional reflexivo. In: NÓVOA, A. (Ed.). Os professores e sua formação. Lisboa: Dom Quixote, 1992.

HILGERT, J. G. A construção do texto "falado" por escrito: a conversação na internet. In: PRETI, Dino (Org.). Fala e escrita em questão. São Paulo: Humanitas, FFLCH/USP, 2000. 
JONSSON, Ewa. Electronic discourse - On speech and writing on the internet. 1998. Disponível em: <http://www.ludd.luth.se/users/ jonsson/D-essay/ElectronicDiscourse.html>. Acesso em: jun. 2002.

KENSKI, V. M. O papel do professor na sociedade digital. In: CASTRO, A. de; CARVAlHO, A. M. P. dae. (Orgs.). Ensinar a ensinar: didática para a escola fundamental e média. São Paulo: Pioneira Thomson Learning, 2001.

KHAN, B. (Ed.) Web-based instruction. Englewood Cliffs, NJ: Educational Tecnhology Publications, 1997.

KOCH, I. G. V. A inter-ação pela linguagem. São Paulo: Contexto, 1995.

Argumentação e linguagem. São Paulo: Cortez, 1993.

LANTOLF, J. P. Sociocultural Theory and Second Language Learning. Oxford: Oxford University Press, 2000.

LEONTIEV, A. N. The Problem of Activity in Psychology. In: WERSTCH, James. V. (Ed.) The concept of activity in Soviet Psychology. New York: Sharpe, 1979. p. 37-71.

LUPICCINI, R. Toward a conversation system modeling research methodology for studying computer-mediated learning communities. Revue de l'Education à distance, v. 17, n. 2, p. 87-101, 2002.

MARCUSCHI, L. A. Gêneros textuais emergentes e atividades lingüísticas no contexto da tecnologia digital. In: SEMINÁRIO DO GRUPO DE ESTUDOS LINGÜÍSTICOS DO ESTADO DE SÃO PAULO, 50., São Paulo, maio de 2002. Conferência de abertura.

MARTINS FONTES, M. C. Aprendizagem de inglês via internet: descobrindo as potencialidades do meio digital. 2002. Tese (Doutorado em Lingüística Aplicada ao Ensino de Línguas) - Pontifícia Universidade Católica de São Paulo, São Paulo.

MELÃO, C. C. C. 2001. Práticas discursivas em transformação: aulas e sessões reflexivas. Dissertação (Mestrado em Lingüística Aplicada ao Ensino de Línguas) - Pontifícia Universidade Católica de São Paulo, São Paulo. 
MILES, M.; HUBERMAN, A. Qualitative data analysis. 2. ed. Thousand Oaks, CA: Sage, 1984.

MORAES, M. C. (Org.). Educação a distância: fundamentos e práticas. Campinas:UNICAMP/NIED, 2002.

MOTTERAM, G. The role of synchronous communication in fully distance education. Australian Journal of Educational Technology, v. 17, n. 2, p. 131-149, 2001. Disponível em: <http:// www.ascilite.org.au/ajet/ajet17/motteram.html>. Vários acessos.

MURRAY, D. E. When the medium determines turns: turn-taking in computer conversation. In: COLEMAN. (Ed.). Working with language. Berlin/New York: Mouton De Gruyter, 1989.

PALMA, D. V.. Gêneros textuais e sua relação com o passado e o presente. In: CONGRESSO BRASILEIRO DE LÍNGUA PORTUGUESA, 10., PUC-SP, São Paulo, 2004. Comunicação oral.

PIESCO, P. O discurso da sala de aula e o processo de ensino/ aprendizagem de inglês como língua estrangeira. 1999. Dissertação (Mestrado em Lingüística Aplicada ao Ensino de Línguas) - Pontifícia Universidade Católica de São Paulo, São Paulo.

PILKINGTON, R.; TREASURE-JONES, T.; KNESER, C. The tutor's role: an investigation of participant roles. In: CMC Seminars Using Exchange Structure Analysis. Proceedings of the Analysing Educational Dialogue Interaction Workshop at AIED. 1999 Disponível em: <http://cbl.leeds.ac.uk/ tamsin/ dialogueworkshop/ pilkington-tutorsrole.pdf $>$. Vários acessos.

PITOMBEIRA, C. V. A presença de ensino no chat do curso "Leitura Instrumental em Inglês via Internet": uma análise de conteúdo. 2003. Dissertação (Mestrado em Lingüística Aplicada ao Ensino de Línguas) - Pontifícia Universidade Católica de São Paulo, São Paulo.

PRETI, O. Autonomia do aprendiz na educação a distância: significados e dimensões. In: PRETI, O. (Org.). Educação a distância: construindo significados. Cuiabá: NEAD/IE; Brasília: Plano, 2000. 
RAMOS, R. C. G.; FREIRE, M. M. Curso de leitura instrumental via rede: da preparação à concretização. In: INTERCÂMBIO DE PESQUISAS EM LINGÜÍSTICA APLICADA, 10., São Paulo. Caderno de Resumos... São Paulo, PUCSP, 2000, p. 57.

ROURKE, L.; ANDERSON, T.; GARRISON, D. R.; ARCHER, W. Assessing social presence in asynchronous text-based computer conferencing. Journal of Distance Education, v. 14, n. 2, 2001. Disponível em: <http://cade.athabascau.ca/vol14.2/ rourke_et_al.html >. Vários acessos.

SABBAG, M. C. O chat e a percepção lingüística em um curso de inglês on-line. 2002. Dissertação (Mestrado em Lingüística Aplicada e Estudos da Linguagem) - Pontifícia Universidade Católica de São Paulo, São Paulo.

SCHÖN, D. A. Formar professores como profissionais reflexivos. In: NÓVOA, A. (Coord.). Os professores e a sua formação. Lisboa: Publicações Dom Quixote, 1997. p. 77-92.

SILVA LEITE, L.; SILVA, C. M. T. A. Educação a distância capacitando professores: em busca de novos espaços para a aprendizagem. 1998. Disponível em: < http://www.Intelecto.net/ead/ ligia-cris.htm>. Vários acessos.

VALENTE, J. A. Educação a distância: uma oportunidade para mudança no ensino. In: MAIA, C. (Org.). Ead.br: educação a distância no Brasil na era da internet. São Paulo: Anhembi Morumbi, 2000.

VYGOTSKY, L. S. [1934] Pensamento e linguagem. São Paulo: Martins Fontes, 1993.

WADT, M. P. Questões de avaliação de design de um curso de inglês online. 2002. Dissertação (Mestrado em Lingüística Aplicada e Estudos da Linguagem) - Pontifícia Universidade Católica de São Paulo, São Paulo.

WERTSCH, J. [1998] Vygotsky and Bakhtin on Community. 2000. (mimeografado) 